\title{
WASTE VALUE POTENTIAL ANALYSIS OF MUNICIPAL SOLID WASTE PRODUCED IN THE PERI-URBAN AREA OF ZHAOQUANYING, CHINA
}

\author{
VICKY SHETTIGONDAHALLI EKANTHALU ${ }^{1}$, SAFWAT HEMIDAT ${ }^{1}$, SUSANNE HARTARD $^{2}$, \\ GERT MORSCHECK ${ }^{1}$, MONA-MARIA NARRA ${ }^{1}$, SATYANARAYANA NARRA ${ }^{1,3}$, \\ JAN SPRAFKE ${ }^{1} \&$ MICHAEL NELLES ${ }^{1,3}$ \\ ${ }^{1}$ Faculty of Agriculture and Environmental Science, Universität Rostock, Germany \\ ${ }^{2}$ Environmental Campus Birkenfeld, University of Applied Sciences Trier, Germany \\ ${ }^{3}$ Deutsches Biomasseforschungszentrum (DBFZ), Germany
}

\begin{abstract}
The recovering and recycling of municipal solid waste (MSW) plays a most crucial role in sustainable waste management and environmental preservation. The rapid urbanization and migration of people is urging the bigger cities of china to handle significantly higher amount of waste. Likewise, the overdependence of peri-urban regions like Zhaoquanying town (ZQY) on bigger cities is making the concept of recycling and recovery a major challenge and simultaneously causing a higher burden on urban areas for sustainable waste management. In this concern, it is crucial to make peri-urban regions like ZQY self-reliant in their waste management. The current study provides the integration of experimental analysis and theoretical evaluation to determine the waste value potential of the MSW produced in ZQY. The experimental sorting analysis of MSW in ZQY has revealed that the major component of MSW consists of recoverable waste with an average of $28 \%$ (kitchen and other organic waste) and recyclable waste with an average of $20 \%$ (paper, plastic, and metal). Despite the having a higher amount of recoverable and recyclable waste, all the produced waste in ZQY is currently ending up in the Shunyi central incineration plant without efficient waste value recovery. The experimental analysis from the organic waste in ZQY has proved to have a higher potential in producing better quality methane and compost. The analysed results reveal that organic waste produced in ZQY has comparatively higher value potential than the recyclable waste available in ZQY, and the total estimated value potential of municipal waste produced in ZQY is between 2.93-3.66 million Yuan/year. The outcome of this study will provide policymakers with the first-hand information and reasoning for directing efforts to achieve waste recovery and recycling in their current waste management practice in ZQY.
\end{abstract}

Keywords: municipal solid waste in China, waste management, waste value, anaerobic digestion, composting, waste recycling.

\section{INTRODUCTION}

The steady rise in the human population has resulted in the generation of a large quantity of waste. Especially developing countries like China have a relatively higher composition of bio-waste which together with the challenges (environmental, social, and economic) provides various opportunities for the production of value-added products. In China, the average per capita volume of municipal waste in cities is $1.17 \mathrm{~kg} / \mathrm{day}$, in townships $0.79 \mathrm{~kg} / \mathrm{day}$, and in villages $0.5 \mathrm{~kg} /$ day [1], [2]. According to the Statistical Yearbook of Urban and Rural Construction (Ministry of Housing and Urban-Rural Development of People's Republic of China, MOHURD 2020), 53\% of China's municipal waste was disposed of in landfills in 2017. Another study shows that in 2014 only $10 \%$ of solid municipal waste generated in villages was properly treated [1]. Several developed countries such as Belgium, Denmark, Germany, Japan, and Sweden have a municipal waste reuse index of over $90 \%$ [3]. Bio-digestion, composting, incineration, and recycling are the most popular methods of treating organic and inorganic waste to produce useful products such as biogas (heat and 
electricity) and organic fertilizers. Similarly, recyclable waste can be recycled and sent back to the production chain as raw materials creating several economic, energetic, environmental, and social benefits [4].

This research proposes a scenario for treating and reutilising the municipal solid waste produced in Zhaoquanying (ZQY) by bio-digestion, composting, and recycling. The proposed scenario is based upon the household waste analysis, collection of additional data during the on-site visits and discussions, assessment of additional data in the literature comparison that was made within the consortium of the PERIVAL project. Recycling is proposed to understand the value potential for recyclable waste such as paper and cardboard, plastic, glass, and metal that is present in solid waste from ZQY. Among the various bio-waste treatment options, composting and biogas production has gained wide popularity owing to its associated benefits such as hygienization of waste, cost-effectiveness, and waste value creation [5], [6]. In this concern, experimental and theoretical analysis has been conducted on composting and biogas to understand the bio-waste value potential of ZQY.

The study results manifest the environmental benefits and socio-economic potential that can incur by sustainably treating the waste produced in ZQY. Several additional benefits include the reduction in the operational costs of solid waste management and a significant decrease in the overdependence of peri-urban areas (ZQY town) on bigger cities for their waste management. The treatment of organic waste by anaerobic digestion and composting enables in the production of additional energy and bio-fertilizer which can supplement the network of energy and fertilizer uses in the locals. In addition to the reductions in emission, decrease in the soil and water contamination amongst other potential positive outcomes.

\section{MATERIAL AND METHODS}

\subsection{Study area}

As part of the PERIVAL - Waste to value chains in peri-urban environments projects, ZQY was selected as a pilot town in the periphery of Beijing. ZQY town is a part of the Shunyi district's administrative divisions. ZQY town consists of 24 villages with 30,182 inhabitants and produces approximately 38 tons of municipal waste/day. ZQY was particularly selected taking into account of eco-industrial potential in intensive horticulture in the Beilangzhong district. The waste from 24 villages of the ZQY municipality is collected every day from the doorstep and transported to a central waste transfer station in ZQY and treated together. Delivered waste is treated together by compacting to remove leachate and transported further to a centralized waste incineration plant in Shunyi and incinerated leaving behind lots of recyclable and removable resources. ZQY has the optimal prerequisite to link the produced organic waste (biogas and/or heat, electricity, and fertilizer) to heat greenhouses for heated orchid growing in greenhouses and to fertilize the crops. The primary and practical aim of this research is to explore the waste value potential of the municipal waste produced in ZQY which can later be used as a model study for analysing waste value potential in typical Chinese peri-urban settlement areas. In this concern this research integrates the experimental and literature data to provide the detailed analysis results on biogas production, composting, and recycling.

\subsection{Waste sampling procedure and sorting analysis}

The sorting analysis was carried out on the mixed residual waste consisting of waste materials with high heterogeneity. The waste for sorting analysis was delivered from the central waste 
transfer station of ZQY before compaction. The waste sorting analysis nomenclatures were adapted from literature data [7], [8] and optimized to fit the local waste fraction behavior (see Fig. 1). The sorting analysis was carried out in an open area with the presence of a roof to restrain the addition of rainwater or moisture that can alter the characteristics of waste. To understand the seasonal waste composition changes, two separate waste sorting analysis was carried out comprising of one each in spring 2019 (27 March-1 April) and summer 2019 (5-11 July). The obtained waste samples were initially sieved using a $40 \mathrm{~mm}$ sieve and the coarse fraction with size $>40 \mathrm{~mm}$ was manually sorted by hand. During the sorting analysis, qualified samples were filled into paper bags and pre-dried using a makeshift ventilator system and transported to Germany to determine the physical and chemical properties of the collected sample. However, glass, metals, and mineral wastes have no heating value and are relatively inert, thus these waste streams were excluded from further chemical analysis. The representative samples of kitchen waste, other-organic waste, and fine fractions $(<40 \mathrm{~mm})$ were finely grounded to make homogeneous samples of grain size $3 \mathrm{~mm}$ and were chemically analysed in Germany.

\subsection{Biogas}

The biogas analysis was carried out at the laboratory site of the University of Rostock equipped with 50 batch-fermenters. Each batch-fermenter is of 60 liters capacity and installed with the magnetic stirrer for continuous stirring. The tests are carried out in accordance with the German directive VDI 4630 at mesophilic temperature. Batch-tests are featured by one-time feeding of the substrate and the logging of the amount and quality of the biogas over the test period. Batch tests aids in analysing the biogas and methane yield of the tested substrate, anaerobic digestion rate, and inhibitory effects of the substrate within the tested range of concentration. According to the directive VDI 4630, the sample mass is determined by the ratio of dry organic matter of the tested substratum and the inoculum. Thus, the sample mass is about $0.2-0.3 \mathrm{~kg}$ of the substrate from ZQY is used with the sewage sludge from a municipal sewage water treatment plant as inoculum.

The produced biogas is stored in special gas sampling bags which are deflated regularly. While deflating, the volume and composition of the produced biogas are measured. The volume is measured by a RITTER drum-type gas meter. For the representation of the results, the gas volume is converted to the volume under normal conditions $(273 \mathrm{~K}, 1013 \mathrm{hPa})$. For the measurement of the gas composition, an EHEIM gas analyzer with sensors for $\mathrm{CH}_{4}, \mathrm{CO}_{2}$, $\mathrm{O}_{2}$, and $\mathrm{H}_{2} \mathrm{~S}$ is used. The duration of the batch test depends on the daily increase of the biogas volume. Tests are aborted if the daily increase is lower than $1 \%$.

\subsection{Composting and recycling}

To assess the value potential of recyclables and compostable waste, an economic model is proposed. In this concern besides the population, accurate estimates of waste quantities generated and collected separately are required. Material that is already separated and diverted can be quantified through direct measurement, but in the case of organics mixed with other waste types, solid waste professionals must extrapolate quantities from known values that represent their percentage of the incoming waste stream. To assess the value potential of recyclables the waste fractions from PPC (paper, paperboard, and cardboard), glass, plastic packaging, and metal are considered. After calculating the actual weight of the sample concerning their dry matter content, the economic value potential is analysed based on the market value for the recyclables in China. Similarly, to understand the value potential 
of composting the waste fractions from kitchen waste, organic waste and $<40 \mathrm{~mm}$ fractions were used. The reason behind considering the waste fractions $<40 \mathrm{~mm}$ is that this fraction of waste had significantly larger amounts of compostable fractions. High levels of heavy metals represent an obvious concern when the compost is destined to be applied to food crops. Similarly, the concentration major elements such as nitrogen, phosphorus, and potassium in the produced organic waste play a major role in deciding the quality of the compost in China. In this concern, the selected samples were analysed for their heavy metal and nutrients concentrations.

\section{RESULTS AND DISCUSSION}

\subsection{Waste sorting analysis}

The waste composition of ZQY was dominated with a fraction $<40 \mathrm{~mm}$ size with a close following of the kitchen waste. Kitchen waste consisting of vegetable and animal-derived food waste constituted for $28.69 \%$ in spring and $18.45 \%$ in summer. Despite the fact that waste composition was dominated with a $<40 \mathrm{~mm}$ fraction, this particular fractions had a major composition of finer kitchen waste and a comparable portion of mineral and hygienic materials.

Fig. 1 depicts the waste composition in ZQY. The fine fraction $(0-10 \mathrm{~mm}$ fraction) includes all kinds of materials present in the waste but represents mainly a mixture of mineral and organic particles. Food waste composition consisting of vegetable and animal-derived food waste constituted for $28.69 \%$ in spring and $18.45 \%$ in summer. Followed by food waste, plastic packaging waste constituted $10.69 \%$ and $15.39 \%$ of total waste generated in spring and summer, respectively. PPC had a composition of 2.65 and $2.62 \%$, glass constitutes 2.28 and $3.74 \%$, and metal with 1.85 and $1.01 \%$ respectively in spring and summer 2019 . A relatively higher fraction of undefined waste was found in spring season $4.39 \%$ compared to summer $1.70 \%$. The composition of textile waste was 3.06 and $4.49 \%$ and hazardous waste/e-waste were 0.55 and $0.27 \%$ in spring and summer season respectively. The percentage of total recyclable waste generated from PPC, glass, and metal constituted 6.78 and $7.37 \%$ in spring and summer, respectively. Except for PPC, the analysis results of recyclables were similar to the results obtained from most of the middle-income countries [9]-[11].
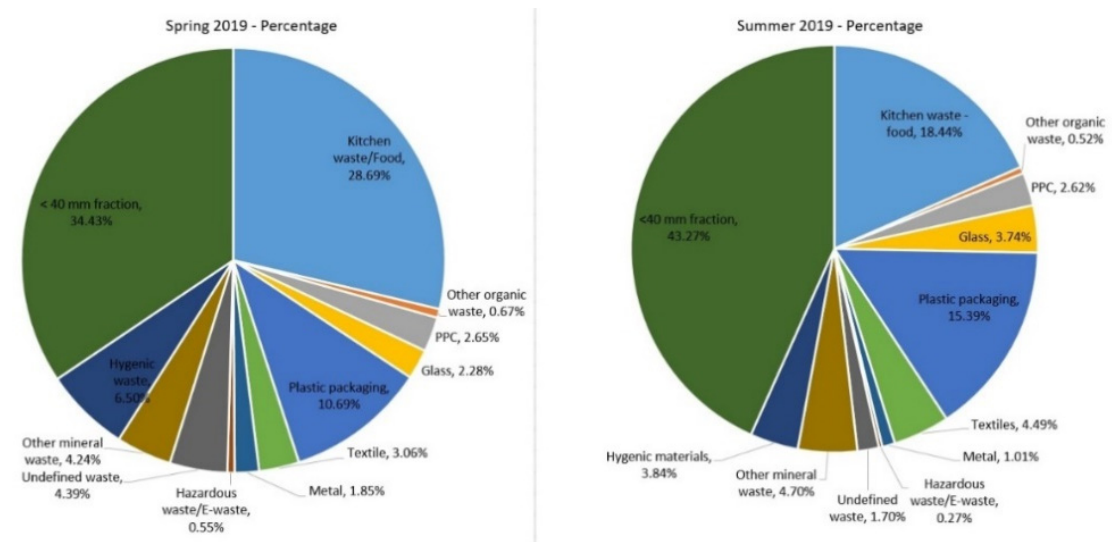

Figure 1: Composition of mixed solid waste in ZQY town in spring and summer 2019. 
There is a significant decrease in the composition of kitchen waste in summer compared to winter. In contrast, the fractions $<40 \mathrm{~mm}$ in the summer season has increased in comparison with winter. As explained earlier, the fraction $<40 \mathrm{~mm}$ is dominated by the finer fractions from kitchen waste and the decrease in the kitchen waste composition in summer can be directly correlated with the increase in the composition of $<40 \mathrm{~mm}$ fractions. The composition of recyclable wastes is lower compared to the average MSW composition in the EU and reason seems to be the source-segregation of recyclables and informal waste collections in ZQY [12]. As explained earlier ZQY is the peri-urban city where most of the produced recyclable wastes are retained by households for further sale or collected by the informal sectors. As the characteristic of the organic waste does not provide the direct recycling/monitory benefit this category of waste ends up in the incineration plant without resource recovery. Variations in the source-segregation pattern in ZQY town may potentially explain differences in the composition of recyclables. Nevertheless, additional factors such as income levels, local sorting guidelines, consumption patterns, demographics, and development, in general, may influence the composition.

\subsection{Biogas potential in ZQY}

\subsubsection{Organic residue available in ZQY for biogas production}

The biogas plant in ZQY can play an important role in addressing the organic waste management and pollution control of agriculture residues. Introducing biogas production in ZQY waste management will aid in the efficient utilization of waste resource and promotes the development of the circular economy. ZQY produces nearly $38 \mathrm{t}$ of MSW/day of which nearly $23.57 \%$ of waste was solely from food/kitchen waste (analysis made in spring and summer 2019). In addition to the organic waste from the household, there is a huge amount of biomass available in the form of agriculture residues in ZQY. Despite the fact of rapid urbanization due to the fact of being located in close proximity to Beijing, agriculture has still been of greater importance in ZQY. According to the Beijing Shunyi 2018 statistical yearbook; wheat, corn, and orchids are the most important crops that are grown in ZQY [13]. According to the literature, there were about 3218 tons of collectible agriculture residue available in ZQY in 2017 [13] (see Table 1). The available biomass in ZQY has significant potential to produce high calorific value methane. The produced methane from available biomass has the potential to reduce GHG emissions by replacing fossil fuels and biomass energy simultaneously providing sustainable waste management pathways.

\subsubsection{Biogas and fermented residue resource potential in ZQY}

Developing the biogas plant in ZQY can exploit the energy value present in the organic residues. Additionally, the utilization of the fermented residue after biogas production can not only help to generate additional revenue but also reduces the use of chemical fertilizer and aids in reducing GHG emissions. Considering all the available biomass in ZQY there is a possibility to set a biogas plant of $238 \mathrm{~kW}$ power (assumption includes 7,000 operation hours/annum and $30 \%$ of electrical and thermal efficiency). According to the experimental analysis there is a potential to produce $586,522.96 \mathrm{~m}^{3} \mathrm{CH}_{4} / \mathrm{a}$, which is equivalent to $1,500 \mathrm{MWh} / \mathrm{a}$ of electricity and 1,228 MWh/a of heat (see Table 1). Considering the selling price of electricity at $0.55 \mathrm{Yuan} / \mathrm{kWh}$ and heat at $0.16 \mathrm{Yuan} / \mathrm{kWh}$ [6] a revenue of 1 .02 million Yuan/year can be generated by selling heat and electricity produced by biomass in ZQY.

The anaerobic fermentation residue contains many major elements such as nitrogen, phosphorus, and potassium that are necessary for plant growth. Co-digestion of agricultural 
waste with the kitchen waste produced in ZQY can produce approximately 5,417.48 tons of fermented residue/a. Additionally, the economic feasibility of any biogas plant greatly depends on the marketability of the produced digestate. Co-digestion of agricultural waste with kitchen waste produced in ZQY can produce 5,417 tons of digestate/a. Considering the selling price of the digestate of $160 \mathrm{Yuan} / \mathrm{t}$, there is a possibility to produce additional revenue of 0.87 million Yuan/a.

Table 1: Methane and fermented residue potential of the biomass produced in ZQY.

\begin{tabular}{|l|c|c|c|}
\hline Substrate & $\begin{array}{c}\text { Availability } \\
(\mathrm{t} / \mathrm{a})\end{array}$ & $\mathrm{CH}_{4}$ potential $\left(\mathrm{m}^{3} \mathrm{CH}_{4} / \mathrm{a}\right)$ & $\begin{array}{c}\text { Fermented } \\
\text { residue t/a }\end{array}$ \\
\hline \multicolumn{4}{|c|}{ Municipal waste in ZQY } \\
\hline Kitchen waste ZQY & $3,269.15$ & $189,415.55$ & $2,970.23$ \\
\hline \multicolumn{4}{|c|}{ Collectable agriculture residue in ZQY [13] } \\
\hline Corn-cob-husks-silage & 748.00 & $125,745.98$ & 508.94 \\
\hline Flower residues (cash crop) & 840.00 & $29,739.36$ & 783.933 \\
\hline Wheat straw & $1,630.00$ & $241,622.07$ & $1,154.37$ \\
\hline Sum & $6,487.15$ & $586,522.96$ & $5,417.48$ \\
\hline
\end{tabular}

\subsection{Compost potential in ZQY}

\subsubsection{Evaluation of ZQY raw organic waste composition for composting}

To evaluate the compost potential from ZQY the compostable waste fractions from kitchen waste, other organic waste, and fractions $<40 \mathrm{~mm}$ size were considered (see Fig. 1). The produced waste in ZQY had the typical waste characteristics of most developing countries, such as high moisture content and large organic fractions. This particular characterises of the waste has significantly high potential to hinder the incineration or direct heat recovery.

The composition of the total waste delivered shows that the fresh matter in the waste for both trials (spring and summer 2019) was strongly dominated by organics. The overall waste composition consists of three waste fractions with the potential to be composted and sums up to $63 \%$ of total generated waste (Kitchen waste, other organic waste, and $<40 \mathrm{~mm}$ fractions). Diversity in organic waste creates promising opportunities for optimal utilization of this waste, specifically concerning the production of high quality finished compost. Organic waste contains kitchen waste (nitrogen source) and garden waste (carbon source) guarantees the suitable $\mathrm{C} / \mathrm{N}$ ratio needed for efficient decomposition. This is due to the fact that the quality of the compost produced depends largely on the level of the $\mathrm{C} / \mathrm{N}$ start-up ratio and the quality of constituents within the mixture.

\subsubsection{Evaluation of the chemical properties of ZQY raw organic waste}

High levels of heavy metals represent an obvious concern when the compost is destined to be applied to food crops [14]. Similarly, the concentration of major elements such as nitrogen, phosphorus, and potassium in the produced organic waste plays a major role in deciding the quality of the compost. Heavy metals do not degrade during the composting process and always become more concentrated due to microbial degradation. Heavy metals in compost products are sourced from the raw materials that have been subjected to composting. In this context, analysis results showed that the resulting heavy metal and nutrients in ZQY raw organic materials were appropriate with the limits set by urban waste for agriculture use, China [15] and ordinance on the recovery of bio-waste on agricultural, forestry, and horticultural uses, Germany [16] (see Table 2). 
Table 2: Heavy metal and nutrients concentrations of ZQY raw organic materials compared with Chinese [15] and German standards[16].

\begin{tabular}{|c|c|c|c|c|}
\hline \multirow{2}{*}{ Parameter } & \multirow{2}{*}{$\begin{array}{l}\text { Range in ZQY } \\
\text { organic waste }\end{array}$} & \multirow{2}{*}{$\begin{array}{l}\text { Control standards for } \\
\text { urban wastes for } \\
\text { agriculture use in China }\end{array}$} & \multicolumn{2}{|c|}{$\begin{array}{c}\text { German standards } \\
\text { BioAfV, } 2017\end{array}$} \\
\hline & & & Class A & Class B \\
\hline \multicolumn{5}{|c|}{ Heavy metal concentration } \\
\hline $\mathrm{Pb} \mathrm{mg/kg}$ & $2.94-26.70$ & $<50$ & $<150$ & $<100$ \\
\hline $\mathrm{Cd} \mathrm{mg/kg}$ & $<0.40$ & $<3$ & $<1.5$ & $<1.0$ \\
\hline $\mathrm{Cr} \mathrm{mg} / \mathrm{kg}$ & $6.48-69.10$ & - & $<100$ & $<70$ \\
\hline $\mathrm{Cu} \mathrm{mg/kg}$ & $8.89-59.30$ & - & $<100$ & $<70$ \\
\hline $\mathrm{Ni} \mathrm{mg/kg}$ & $2.39-26.40$ & - & $<50$ & $<35$ \\
\hline $\mathrm{Hg} \mathrm{mg/kg}$ & $0.050-0.053$ & $<2$ & $<1.0$ & $<0.7$ \\
\hline $\mathrm{Zn} \mathrm{mg/kg}$ & $46.80-126.00$ & - & $<400$ & $<300$ \\
\hline As mg/kg & $1.00-2.60$ & $<15$ & $<10$ & $<10$ \\
\hline \multicolumn{5}{|c|}{ Nutrients concentration } \\
\hline $\mathrm{N} \%$ & 1.79 & $>0.5$ & \multicolumn{2}{|c|}{-} \\
\hline $\mathrm{P}_{2} \mathrm{O}_{5} \%$ & 1.13 & $>0.3$ & \multicolumn{2}{|c|}{-} \\
\hline $\mathrm{K}_{2} \mathrm{O} \%$ & 1.33 & $>1$ & \multicolumn{2}{|c|}{-} \\
\hline
\end{tabular}

The content of the heavy metals ( $\mathrm{Pb}, \mathrm{Cd}, \mathrm{Cr}, \mathrm{Cu}, \mathrm{Ni}, \mathrm{Hg}, \mathrm{Zn}$, and $\mathrm{As}$ ) shown in Table 2 indicates that the concentrations of all seven heavy metals and the nutrient concentration were appropriate with the limits set by Chinese and German Standards. The low concentrations of heavy metals are because the waste was generated and collected from the rural area. Usually, the waste generated from rural areas has a very low percentage of heavy metals, in contrast to those that are generated in urban areas (high concentrations of heavy metals).

\subsubsection{Economic feasibility of compost production in ZQY}

To assess the economic benefits of composting in ZQY a model is proposed and the proposed model considers several facts and assumptions as following;

i. 38 tons/day of waste generation

ii. $\quad 100 \%$ waste collection efficiency

iii. $63 \%$ of the collected waste is compostable waste

iv. Composting duration of 12 weeks

v. $30 \%$ volume reduction in windrow piles during composting and

vi. The selling price of compost at 500 Yuan/ton.

With the above assumptions nearly 5825.4 tons/year of finished compost can be produced. Considering the finished compost has $50 \%$ of moisture content, nearly 2912.7 tons/year of finished dry compost can be produced from the waste generated in ZQY. This, in turn, can produce revenue of 1.46 Million Yuan/year from the sales of finished compost. 
Table 3: Recyclables composition of municipal waste from ZQY city, an average of both trial analysis.

\begin{tabular}{|l|c|c|c|c|c|c|c|}
\hline $\begin{array}{l}\text { Recyclable } \\
\text { fractions }\end{array}$ & $\begin{array}{c}\text { Spring } \\
\text { trial } \\
(\%)\end{array}$ & $\begin{array}{c}\text { Summer } \\
\text { trial (\%) }\end{array}$ & $\begin{array}{c}\text { Average } \\
(\%)\end{array}$ & $\begin{array}{c}\text { Average } \\
\text { dry matter } \\
(\%)\end{array}$ & $\begin{array}{c}\text { Amount } \\
\text { (ton/a) }\end{array}$ & $\begin{array}{c}\text { Price/kg in } \\
\text { Yuan [18] }\end{array}$ & $\begin{array}{c}\text { Annual } \\
\text { revenue } \\
\text { (Yuan) }\end{array}$ \\
\hline PPC & 2.65 & 2.62 & 2.64 & 53.17 & 195 & 0.80 & $156,000.0$ \\
\hline Glass & 2.28 & 3.74 & 3.00 & - & 416 & 0.95 & $395,200.0$ \\
\hline $\begin{array}{l}\text { Plastic } \\
\text { packaging }\end{array}$ & 10.69 & 15.39 & 13.00 & 59.52 & 1063 & 0.70 & $744,100.0$ \\
\hline Metal & 1.85 & 1.01 & 1.43 & - & 198 & 0.90 & $178,200.0$ \\
\hline \multicolumn{7}{|c|}{ Total revenue (price vary from city to city) } \\
\hline
\end{tabular}

\subsection{Recyclables potential in ZQY}

\subsubsection{Quantity of recyclables generated in ZQY}

In the recyclable waste category, the composition of PPC is comparatively similar without any major seasonal variations (refer to Fig. 1). The glass composition is relatively higher in summer with $3.74 \%$ and $2.28 \%$ in spring. The plastic packaging fractions have dominating shares in the recyclable waste category with $10.69 \%$ in spring and $15.39 \%$ in summer. Nevertheless, the overall recyclable waste composition is lower compared to the average recyclable produced in the EU [12]. In the recyclable waste category, the composition of PPC is significantly lower not only in comparison with the different economic levels of the counties but also with the same economic level as well. PPC averages about $2.64 \%$ in ZQY in comparison with $9.5 \%$ in other middle-income countries [17], the source-segregation of PPC in ZQY explains it. However, the composition of plastic, glass, and metal almost similar in ZQY with other middle and low-income countries. The difference observed in the composition of ZQY can be related to (i) consumption pattern and geographical factors, (ii) waste management system, (iii) local regulations, (iv) methodology of waste characterization.

\subsubsection{Economic feasibility of recycling the recyclables in ZQY}

Due to the huge recycling potential as a resource, PPC, glass, plastic, and metals waste are subject to recycling obligations with specific quotas as legally stipulated by national guidelines. In the same light, China is currently planning to implement a source-separated collection system for recyclables waste. To this concern, this study helps to identify the value of those recyclable fractions and the economic feasibility of utilizing them. Table 3 shows the most notable valuable recyclable fractions that should be focused and their potential monitory benefits.

The recyclable fraction in Table 3 was sorted from the highly heterogeneous municipal waste from ZQY. Fraction like paper and plastic packaging due to their obvious surface and structural characteristic tends to attract moisture and dirt, with some portion of PPC reacting moisture up to $70 \%$. Hence the separate waste collection is the primary prerequisite for successful waste recycling. However, in this feasibility analysis the recyclable waste produced is calculated according to their dry matter \% enabling the most reliable cost estimations. Considering the waste generation rate of 38 tons/year and $100 \%$ collection efficiency over 365 days of the year, there is a potential to generate 195 tons/year of PPC, 416 tons/year of glass, 1,063 tons/year of plastic packaging, and 198 tons/year of metal. The amount of generated recyclables in ZQY has latent to produce total revenue of 1.47 million Yuan/year. 


\subsection{Total estimated waste value potential of the municipal waste produced in ZQY}

Table 4 represents the summary of the total value potential of the municipal waste generated in ZQY. The obtained results depict that organic waste produced in ZQY has comparatively higher value potential than the rest of the available wastes. The total estimated value potential of municipal waste produced in ZQY is between 2.93-3.66 million Yuan/year (depending on the choice of treatment technology; Biogas + recycling or composting + recycling).

Table 4: Total estimated value potential of the municipal waste produced in ZQY.

\begin{tabular}{|l|l|c|c|}
\hline $\begin{array}{l}\text { Treatment } \\
\text { method }\end{array}$ & Value product & $\begin{array}{c}\text { Estimated value in } \\
\text { million Yuan/year }\end{array}$ & $\begin{array}{c}\text { Total revenue in } \\
\text { million Yuan/year }\end{array}$ \\
\hline \multirow{2}{*}{ Biogas } & Heat and electricity & 1.02 & \multirow{2}{*}{1.89} \\
\cline { 2 - 3 } & Fermented residue & 0.87 & 1.46 \\
\hline Composting & Compost & 1.46 & \multirow{2}{*}{1} \\
\hline \multirow{5}{*}{ Recycling } & PPC & 0.15 & \multirow{2}{*}{1.47} \\
\cline { 2 - 3 } & Glass & 0.39 & \\
\cline { 2 - 3 } & Plastic packaging & 0.74 & \multicolumn{1}{|c}{} \\
\cline { 2 - 3 } & Metal & 0.18 & \\
\hline
\end{tabular}

\section{CONCLUSION}

The study depicts the detailed value potential of the waste produced in ZQY town. The illustrated results have a high potential to serve as a basis for the municipal decision-makers and to use as a model study for analysing waste value potential in typical Chinese peri-urban settlement areas. From the environmental and economic viewpoint, composting and biogas production can be beneficial in treating the organic fractions of solid waste in ZQY. The overall, waste composition of ZQY and its chemical properties indicate that the composting and biogas production is an economical and sustainable alternative to treat the waste produced in ZQY. Similarly, recycling the recyclables also provides an opportunity to generate huge additional revenue. However the separate waste collection system is highly recommended to successfully recycle the recyclables. The self-reliance of waste management in the peri-urban region like ZQY can significantly reduce the overburden on bigger cities in their waste management. Additionally, the obtained results depict that organic waste produced in ZQY has a comparatively higher value potential than the rest of the available wastes. This gives major reasoning for making bio-waste management and value recovery a primary focus in ZQY. Conversion of organic waste in ZQY into compost and biogas can bring unparalleled economic, environmental, and social benefits and has a higher potential in developing sustainable waste management in ZQY by promoting a low-carbon circular economy.

\section{ACKNOWLEDGEMENT}

The authors acknowledge the Federal Ministry of Education and Research (BMBF) for financing this study via the PERIVAL - Waste to value chains in peri-urban environment project.

\section{REFERENCES}

[1] Dezhen Chen, L.Y.H.W.P.H., Pyrolysis technologies for municipal solid waste: A review. Waste Management, 34(12), pp. 2466-2486, 2014. 
[2] National Bureau of Statistics of China, China Statistical Yearbook, China Statistics Press, 2017.

[3] Lino, F.A.M. \& Ismail, K.A.R., Analysis of the potential of municipal solid waste in Brazil. Environmental Development, 4, pp. 105-113, 2012.

[4] Lino, F., Bizzo, W.A. \& Silva, K.A.R.I.E.P., Energy impact waste recyclable in a Brazilian Metropolitan. Resources, Conservation and Recycling, 54, pp. 916-922, 2010.

[5] Oazana, S. et al., A flexible control system designed for lab-scale simulations and optimization of composting processes. Waste Management, 72, pp. 150-160, 2018.

[6] Duana, N., Lin, C., Wang, X.D., Zhang, X.J. \& Hou, Y., Study on the effect of biogas project on the development of low-carbon circular economy: A case study of Beilangzhong eco-village. Procedia Environmental Sciences, 5, pp. 160-166, 2011.

[7] Bilitewski, B., Wagner, J. \& Reichenbach, J., Best Practice Municipal Waste Management, Umweltbundesamt: Dessau-Roßlau, 2018.

[8] Riber, C., Petersen, C. \& Christensen, T.H., Chemical composition of the material fraction in Danish household waste. Waste Management, 29(4), pp. 1251-1257, 2009.

[9] Towprayoon, S. et al., Waste generation, composition and management data. Refinement to the 2006 IPCC Guidelines for National Greenhouse Gas Inventories, 2019.

[10] Saeed, M.O., Hassan, N.M. \& Mujeebu, M.A., Assessment of municipal solid waste generation and recyclable materials potential in Kuala Lumpur, Malaysia. Waste Management, 29, pp. 2209-2213, 2009.

[11] Srivastava, V., Ismail, S.A., Singh, P. \& Singh, R.P., Urban solid waste management in the developing world with emphasis on India: challenges and opportunities. Reviews in Environmental Science and Bio/Technology, 14, pp. 317-337, 2015.

[12] Bidlingmaier, W., Sidaine, J.-M. \& Papadimitriou, E., Separate collection and biological waste treatment in the European Community. Reviews in Environmental Science \& Bio/Technology, 3, pp. 307-320, 2004.

[13] Shunyi Bureau of Statistics, The Statistical Yearbook of Beijing Shunyi 2018, China Statistics Press: Beijing, 2018.

[14] Papadimitrou, E., Barton, J. \& Stentiford, E., Sources and levels of potentially toxic elements in the biodegradable fraction of autoclaved non-segregated household waste and its compost/digestate. Waste Management and Research, 26, pp. 419-430, 2008.

[15] Ministry of Environmental Protection of the People's Republic of China, Control Standards For Urban Wastes For Agricultural Use - GB8172-87, 1987.

[16] Bioabfallverordnung - BioAbfV, Verordnung über die Verwertung von Bioabfällen auf landwirtschaftlich, forstwirtschaftlich und gärtnerisch genutzten Böden, Bundesministeriums der Justiz, 2017.

[17] Edjabou, M.E. et al., Municipal solid waste composition: Sampling methodology, statistical analyses, and case study evaluation. Waste Management, 36, pp. 12-23, 2014.

[18] Thomas Dorn, M.N.S.F., Circular Economy in China. ISWA, 2010. 